\title{
RECEPCIÓN DE HERÓDOTO, CTESIAS Y JENOFONTE EN GALENO*
}

\author{
Juan Antonio López Férez \\ Universidad Nacional de Educación a Distancia (UNED), Madrid \\ jalferez@flog.uned.es
}

\begin{abstract}
RESUMEN
Galeno cita a los tres historiadores recogidos en este trabajo (Heródoto, Ctesias y Jenofonte) como argumento de autoridad, bien en apoyo de teorías y prácticas, médicas o de otro tipo (así sobre el daño que la nieve causa en los ojos, y acerca de la importancia de la belleza), bien como garantía de términos especiales poco utilizados ya en el siglo II d. C.

Palabras Clave: Galeno, recepción Heródoto, Ctesias, Jenofonte.
\end{abstract}

\section{ABSTRACT}

«Reception of Herodotus, Ctesias and Xenophon on Galen». Galen cites the three historians collected in this paper (Herodotus, Ctesias and Xenophon) as an argument of authority, or in support of theories and practices, medical or otherwise (as the damage that snow causes in the eyes, and of the importance of beauty), or as a guarantee of special terms little used in the second century $\mathrm{AD}$.

KeY WORDS: Galen, reception Herodotus, Ctesias, Xenophon.

1. Hace poco he revisado la presencia del término historía y algunos otros de su familia léxica en las obras de Galeno, así como las menciones de historiadores relevantes en el citado ${ }^{1}$. El gran médico de Pérgamo es una fuente de primera magnitud por sus muchos conocimientos literarios y científicos, y, en ese sentido, la historia y los historiadores no le fueron ajenos.

Galeno (129-216 d. C.) ${ }^{2}$, nacido en Pérgamo, murió quizá en Roma o en su ciudad natal, aunque la tradición árabe habla de Egipto y de Sicilia. Su biografía, recogida parcialmente por el propio autor, nos explica los extraordinarios cimientos de su enorme obra: el ambiente familiar desahogado en que vivió; la preocupación de su padre, arquitecto, por que obtuviera la mejor educación; su paso por los centros más reputados de su época en busca de alcanzar la más alta formación en numerosas disciplinas, no solo en medicina (Pérgamo, Esmirna, Corinto, Alejandría y su regreso a la primera nombrada, donde durante casi cuatro años (157-161) fue médico de los gladiadores, ampliando mucho sus conocimientos anatómicos y dietéticos); sus viajes por diversos lugares del imperio (Siria, Palestina, Chipre, Licia, Lemnos) 
buscando productos necesarios para la preparación de ciertos fármacos; su llegada y primera estancia en la capital del imperio, Roma (162-166 d. C.), donde hizo varias demostraciones públicas de sus conocimientos anatómicos y logró tener por amigos y clientes a altos personajes imperiales; su regreso a Pérgamo (166); su viaje a Aquilea, llamado por los emperadores Lucio Vero y Marco Aurelio (fines del 168), preocupados por la peste que atacaba al ejército; su segunda estancia en Roma (169-?); la fama que supo ganarse poco a poco, hasta llegar a ser médico personal de tres emperadores (Marco Aurelio, Cómodo y Septimio Severo). Su producción literaria conservada es la segunda en extensión dentro de la literatura griega (según el TLG, Juan Crisóstomo, con 4.071.012 palabras, es el primero; luego, Galeno, 2.502.902), a pesar de la pérdida de numerosos tratados mencionados por él mismo. En griego, disponemos de unas ciento catorce obras, algunas dudosas. Por lo demás, nos han llegado, total o parcialmente, al menos seis tratados en traducción árabe, no transmitidos en griego; de otros cinco podemos leer solo la versión latina, o la latina y la árabe. Relevante es también el Pseudo-Galeno, con otras veinticinco obras conservadas en griego.

\section{GALENO COMO FUENTE LITERARIA Y CIENTÍFICA}

Desde hace unos años los estudiosos vienen revisando la importancia de Galeno como lector, receptor y transmisor de numerosos autores y obras, no solo médicas, de la literatura griega. Sabemos que el polígrafo dispuso de magníficas bibliotecas a su alcance - entre ellas, sucesivamente, la de Pérgamo, a la que se le calculaban unos 200.000 volúmenes en sus momentos de máximo esplendor, y las de Roma,

* Trabajo realizado dentro del Proyecto FFI 2014-55220-R del Ministerio de Economía y Competitividad.

${ }^{1}$ "Historía, historéo, historikós y los historiadores en Galeno». Será publicado en el volumen que recoja los trabajos presentados durante el Congreso Historia y Medicina en la Antigüedad (Universitat de Barcelona, Facultat de Lletres, 2 de febrero de 2017).

${ }^{2}$ Entre otros muchos estudios conspicuos sobre el escritor figuran Schlange-Schöningen 2003; Hankinson 2000 y (ed.) 2008; Gill-Whitmarsh-Wilkins (eds.) 2009; Boudon-Millot 2012; Mattern 2013; etc. Por otra parte, como introducción a la inmensa bibliografía dedicada a Galeno y renovada continuamente en las revistas especializadas, es útil todavía el trabajo de Kollesch-Nickel 1994; importantes también son las contribuciones bibliográficas de García Sola 1994, y Quiroga Puertas-García Sola 2013. Con respecto a los tratados galénicos, sigo las denominaciones latinas utilizadas por el Corpus galenicum (= CGB, dentro de esta aportación), valioso instrumento bibliográfico de uso libre en internet. Para las citas, véase en la Bibliografía lo que digo tras referirme a la edición de Kühn. Por lo general, en las abreviaturas de obras griegas o latinas, me atengo, dentro de la literatura griega, al Greek-English


dase a http://dge.cchs.csic.es/lst/2lst-int.htm (DGE); y, en lo pertinente a la latina, al Latin-English Dictionary de Lewis-Short (1879'): consúltese http://latinlexicon.org/LNS abbreviations.php). Todas las traducciones son mías. 
donde mención especial merecen las imperiales — así como de una cuidada selección privada $^{3}$, muy nutrida tanto por libros comprados como por los que iba encargando que le copiaran a partir de ejemplares existentes en la urbe.

\section{HISTORIADORES CITADOS POR SU NOMBRE}

Hoy, gracias al TLG, manejado siempre con cuidado y comprobación de los datos, sabemos que, respecto a los grandes historiadores griegos, Galeno contiene varias referencias: Heródoto (4), Tucídides (25)4, Ctesias de Cnido (3) y Jenofonte (7)5. Procuraré recoger lo esencial de los tres indicados en el título de esta aportación.

\subsection{Heródoto (4)}

De las 18 ocasiones en que el antropónimo Heródoto aparece en Galeno solo cuatro hacen referencia al historiador de Halicarnaso ${ }^{6}$. Las otras aluden a dos médicos homónimos?.

\footnotetext{
${ }^{3}$ Véase Nutton, 2009, quien señala el poco interés del pergameno por los historiadores, si exceptuamos a Tucídides. López Férez 1992, ofrece un trabajo introductorio sobre Galeno como receptor y transmisor de la literatura griega.

${ }^{4}$ El estudio correspondiente, «Recepción de Tucídides en Galeno», aparecerá próximamente en el Homenaje al Profesor Alberto Bernabé, en prensa.

${ }^{5}$ Valiéndome del TLG y a la vista de las Historias de la literatura griega más recomendadas, he rastreado la presencia en Galeno de los historiadores anteriores a él. No queda excluido que pueda aparecer algún nombre más que los aquí recogidos, dado el elevado número de historiadores de época helenística e imperial perdidos para nosotros. Por otra parte, el médico recoge en ocasiones citas sin decir de quién las ha tomado ni de qué obra o libro de la misma. Queda abierto, pues, el camino para futuros investigadores.

${ }^{6}$ La obra de Heródoto (484-después del 425 a. C.) ha sido siempre de gran interés para los estudiosos de historia de la medicina. Thomas, 2002, ha subrayado la importancia en el historiador de la descripción de ciertas curas y tratamientos, deteniéndose en las semejanzas con los textos hipocráticos. Por otro lado, respecto al proceso histórico y el modo de enjuiciar a los pueblos con quienes los griegos fueron entrando sucesivamente en contacto hay curiosos paralelos entre los tratados hipocráticos de primera hora y ciertos textos herodoteos: véase Nutton $2013^{2}: 51$. Un estudio reciente sobre la anatomía en el historiador es el de Sierra Martín, 2014. Para la recepción de dicho autor en la posteridad, acúdase a Priestley 2014, y Priestley-Zali 2016.

${ }^{7}$ Conviene distinguir, por un lado, un Heródoto médico (quizá del siglo $\mathrm{V}$ a. C.) que se interesó por los beneficios e importancia de la leche recién sacada, o tomada directamente de las mamas, bien de una mujer, bien de asnas (10.474.17). Por otro, un médico homónimo del siglo I d. C., que se ocupó especialmente de los alimentos (cereales, ante todo: 6.516.12; y otros productos nutritivos: 11.432 .5 ; 441.18; 442.3.6; 443.4) y del pulso (8.751.3), y que investigó y escribió sobre temas referentes a los medicamentos simples (11.430.5).
} 
3.1.1. Nuestro estudioso, hablando de las "partes de la mano", concluye de este modo: «Yo ya tengo dichas todas las partes de la mano. A ti ${ }^{8}$ te interesa leer, no por placer, como el relato de Heródoto, sino para poner en tu memoria cada cosa observada, a fin de que aprendas perfectamente la naturaleza de cada una de sus partes»". Conviene detenerse en dos ideas de lo antes expresado: de un lado, el relato de Heródoto, y, de otro, leer por placer. En primer lugar, la estrecha relación de los términos historía (como título o forma literaria o simplemente relato)-Heródoto la hallamos por primera vez en Aristóteles, dentro de los autores de obra conservada. Se trata de una secuencia en que el estagirita afirma así: «El historiador y el poeta no difieren en expresarse de forma métrica o carente de metro - pues lo de Heródoto podría ponerse en metros y no sería en nada menos historia con metro que sin metros- ${ }^{10}$. En segundo, el único precedente sobre el binomio lectura-placer lo tenemos en Polibio: «Por lo cual nosotros, pretendiendo no tanto el placer de los que me vayan a leer como la utilidad de los que prestan atención, dejando lo demás, hemos sido transferidos a esta parte (sc. del relato histórico)»" ${ }^{11}$.

3.1.2. El investigador, mientras está comentando un texto del libro sexto de las Epidemias hipocráticas ${ }^{12}$, se detiene en el adjetivo $\pi\left\llcorner\tau \cup \rho \omega ́ \delta \eta s^{13}\right.$. En tal ocasión se manifiesta con estas palabras:

${ }^{8}$ Posiblemente Boeto, gran amigo del pergameno, que le dedicó varios tratados referentes a anatomía.

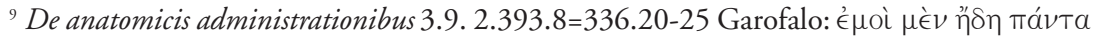

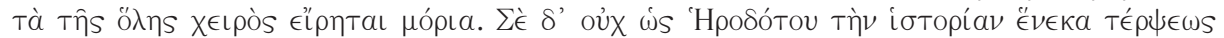

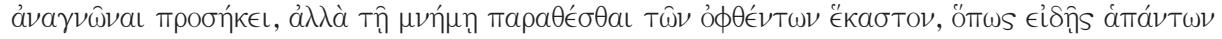

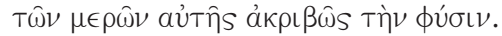

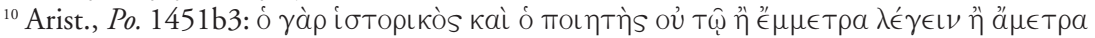



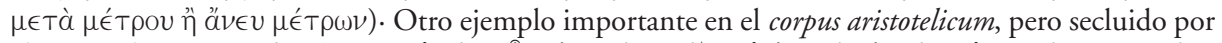

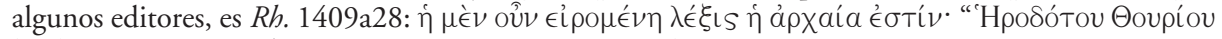

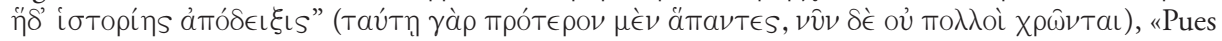
bien, el estilo continuo es el antiguo: 'Esta es la exposición de la historia de Heródoto turio' (ése lo usaban antes todos, pero, ahora, no muchos)». Para el estrecho paralelo Heródoto-historía en la literatura posterior, véanse textos importantes en D. S., 1.37.4; D. H., Th. 5;6;9; Pomp.3; Dem., Eloc. 44; Plu., Moralia 604f; etc.

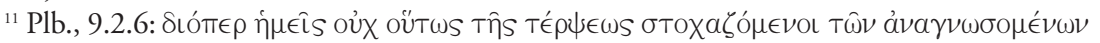

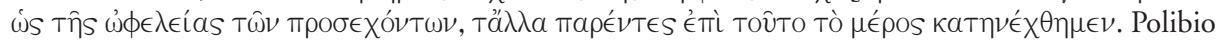
está hablando de que había decidido escribir una historia de hechos presentes, de actualidad, sin genealogías ni recurso a los mitos. Es relevante que nuestro prosista se haga eco de esa interrelación «leer»-«placer», de escasos ecos en la literatura posterior.

${ }^{12}$ Hp., Epid. 6.3.5.5.287.8-9.

${ }^{13}$ El sentido apunta a la sustancia que tiene aspecto de «salvado», es decir, furfurácea. El término era propio de los tratados científicos: Hp. (5), Theoph. (1), Dsc. (5), Erot. (2), Ruf. (1), Gal. (26). Nuestro prosista, pues, lo recogió con frecuencia en sus obras. 
A cuáles llama «furfuráceas» es difícil descubrirlo, si uno no lee solo como historia, como la de Heródoto ${ }^{14}$ y Ctesias ${ }^{15}$, los libros de los médicos antiguos, sino para conseguir algún provecho para las obras del arte (sc. médica). Pero muchos exegetas, descuidándose de eso, especialmente los que emulan el método sofístico, llegan hasta lo fácil del comentario, lo que consiste en la monstración del término, sin comprobar en los enfermos la verdad de lo que se dice $^{16}$.

${ }^{14}$ En apoyo de que se trata del historiador de Halicarnaso tenemos algunos textos que avalan la consideración conjunta de ambos escritores. Estrabón (11.6.3; 3c,688 T Jacoby; Fr. 29 TLG), refiriéndose a una serie de escritores anteriores que habían hablado de diversos pueblos y comarcas sin saber nada verdadero sobre ellos, concluye que «sería más fácil que uno le diera crédito a Hesíodo y Homero cuando hablan de los héroes, y a los poetas trágicos, que a Ctesias, Heródoto y Helanico,

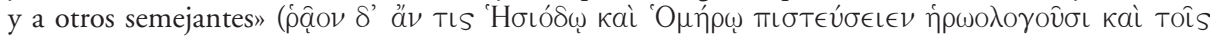

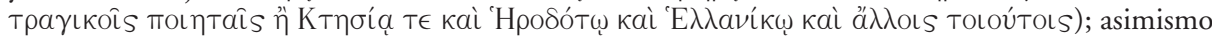
(St., 1.2.35; 3c, 688 Jacoby; Fr. 30 TLG), donde el geógrafo de Amasia se expresa de este modo: «Teopompo lo reconoce al afirmar que narrará mitos en sus historias mejor que Heródoto, Ctesias y

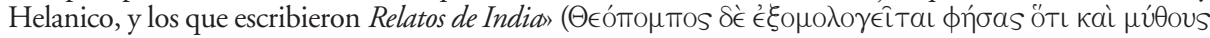

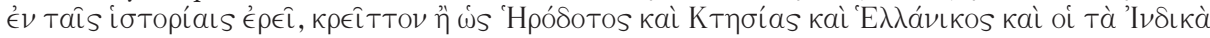

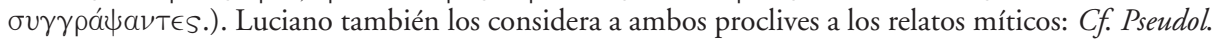
2; VH 2.31. Posteriormente, otros autores, en fuentes distintas, apoyan el mismo criterio.

${ }^{15}$ Ctesias de Cnido, notable historiador y médico, nació en la segunda parte del v a. C. Posiblemente nació hacia el 440, y, aunque no sabemos nada de la fecha de su muerte, sí hay datos para fijar hacia el 397 su vuelta desde Persia a Cnido, donde se estableció definitivamente y escribió sus libros históricos. Como médico personal, acompañó en el 401 a Artajerjes Mnemón en una expedición dirigida contra el hermano de éste, Ciro el Joven. Su obra nos ha llegado en estado muy fragmentario: destacan unos Relatos de Persia (Persiká), en 23 libros, y unos Relatos de India (Indiká), precisamente la monografía más antigua dedicada a ese remoto país. En el terreno médico sabemos que criticó el modo hipocrático de solucionar una luxación de cadera, pues, en fin de cuentas, su formación era cnidia, donde había una famosa escuela médica rival de la coica (Hipócrates, por lo que sabemos, siguió, en buena medida, el método médico coico propio de su patria chica, la isla de Cos); también se ocupó del uso del heléboro con fines médicos. $C f$. Nichols, 2008; 2011; a su vez, Stronk, 2010, revisa las fuentes esenciales para el estudio de las Persiká, a saber, Diodoro de Sicilia, Nicolás de Damasco, Plutarco y Focio. Galeno lo llama «pariente» de Hipócrates, porque también era Asclepiada. Lo menciona en otras dos ocasiones: 18a731.9 y 11, como primer crítico del método seguido por Hipócrates para solucionar la luxación de cadera. Nos ocuparemos de ello más adelante.

${ }^{16}$ In Hippocratis librum vi epidemiarum commentarii vi 3.13.17b33.2=141.1-7 Wenkebach:

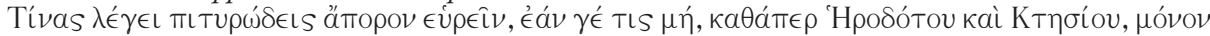

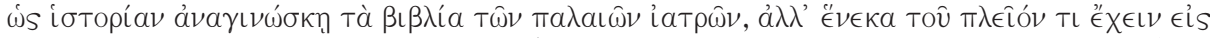



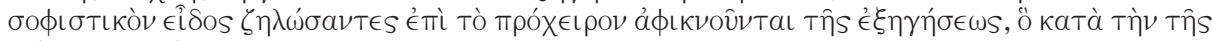

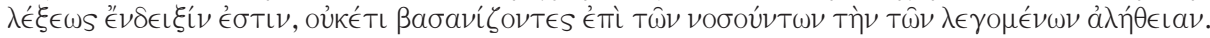
Adviértase la oposición entre leer como historia (o relato) y el hecho de servir de provecho para la medicina. $\mathrm{Al}$ menos tres detalles merecen una rápida explicación: 1. eîdos sophistikón, donde eîdos apunta al modo de actuar, el método, de los sofistas. Pueden verse dos precedentes: Arist., SE 165a; y Phld., Rh. 1.col.41.6ss. El propio médico recurre a la expresión en 17b81.12; 18b858.18; 2. la éndeixis léxeōs, o simple hecho de mostrar la palabra sin entrar en su uso ni significado, es mencionada también en 16.615.7. No hay precedentes literarios; 3. basanizein alétheian, donde hay un uso metafórico novedoso, pues, en realidad, a quien se somete a tortura no es a la verdad, sino a un esclavo (u otro testigo) en busca de la verdad de los hechos, como leemos desde los oradores áticos. Nuestro prosista recurre a la metáfora en otras ocasiones: 6.462.2; 17b347.15. 
3.1.3. Dentro de su exegesis del libro séptimo de los Aforismos hipocráticos, nuestro prosista se detiene en el quincuagésimo ${ }^{17}$, donde se habla del esfacelo (o gangrena) que afecta al cerebro. Precisamente, el médico se extiende, de modo particular, en los términos sphakelizai, sphákelos y gángraina: "Ahora bien, a la necrosis de las partes carnosas a consecuencia de la magnitud de la inflamación, a aquella la llaman con propiedad gangrena los médicos, y a ésa también la llamaban esfacelo los griegos. Por tanto me parece que conforme Heródoto ${ }^{18}$ ha dicho que el muslo de Cambises padecía esfacelo, así también diría uno que el cerebro padece esfacelo» ${ }^{19}$.

\subsubsection{En su Comentario a Sobre las articulaciones, el pergameno está revisando un} pasaje hipocrático ${ }^{20}$ donde se expone que, cuando se ha padecido una luxación de cadera, la pierna correspondiente, por falta de uso, se vuelve fláccida y delgada. Dentro



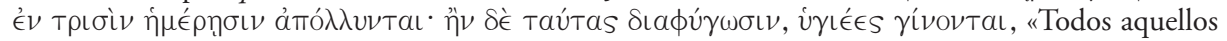
cuyo cerebro padece esfacelo, mueren en tres días; pero si escapan de éstos, llegan a estar sanos».

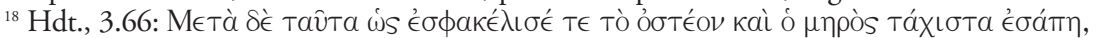

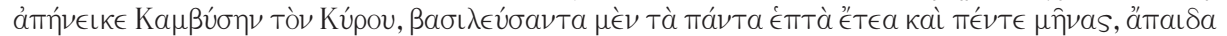

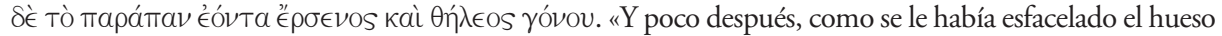
y el muslo se le gangrenó rápidamente, se llevó a Cambises, hijo de Ciro, tras haber reinado, en total, siete años y cinco meses, y estando totalmente sin hijos, ni del género masculino, ni femenino». Hdt., 3.64, relata que, tras haber saltado Cambises sobre su caballo cerca de Ecbatana, localidad de Siria, su espada, saliéndose de la vaina, le hirió en el muslo. El rey, recordando hechos anteriores, medio míticos, pensó, en seguida, que la herida era mortal. Unos veinte días después reunió a sus próceres y les dirigió unas palabras; tras ello, al poco, murió. Por su lado, Ctesias (Per. 12) precisa que fue accidental la herida que Cambises sufrió en el muslo, pero que, a resultas de la misma, murió a los diez días.

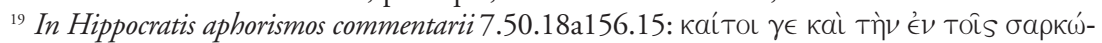

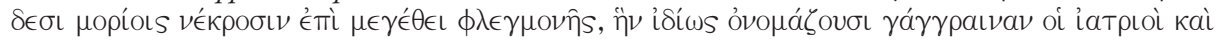




Galeno recurre con frecuencia al gentilicio "E $\mathrm{\lambda} \lambda \eta \nu$ (10 secuencias), plural "E $\lambda \lambda \eta \nu \in S$ (264), para referirse al léxico utilizado por los griegos, especialmente los de los siglos V-IV a. C. Sobre el particular, véase López Férez 2006: 140-159. Un apartado especial merecen los abundantes ejemplos en que el médico hace referencia a la lengua de los griegos en sus distintos niveles: fonético, morfológico, sintáctico, léxico, estilístico, etc. Nos encontramos con numerosas secuencias que nos permiten extraer información sobre las opiniones del médico acerca de la lengua griega en su desarrollo diacrónico, de modo especial, desde el siglo $V$ a.C. hasta sus propios días, es decir, un panorama histórico de setecientos años. Precisamente, en el comentario del estudioso a los Aforismos hipocráticos hallamos en ocho ocasiones, al menos, la frase «los griegos llaman...»; el autor, sin duda, era plenamente consciente de que el tratado hipocrático contenía vocablos arcaicos, raros, fuera de uso ya en el siglo II a.C. Así, leemos: «A la que los griegos, propiamente, y, sobre todo, los atenienses llaman 'consunción', a ésa, pues, Hipócrates la

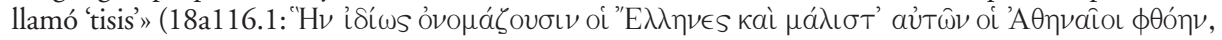

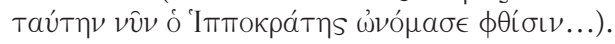

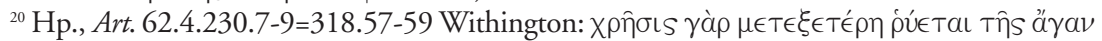

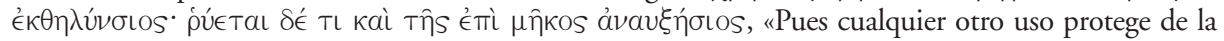
flaccidez excesiva. Y también protege, en cierta medida, del crecimiento en extensión». 
de ese contexto se detiene, de modo singular, en un adjetivo desusado en su época, y, en griego, en general, pero utilizado por Heródoto: «Es posible aprender precisamente a lo largo de Heródoto que metexetérén no significa entre los jonios nada distinto de hetérèn entre nosotros. Pues muchas veces está usado en él, tal como también metexétero $^{21}$. Por tanto es evidente, por medio de éste, lo que para nosotros es mediante tines, aunque, con todo, lo evidente de metexetérou no es tal ${ }^{22}$.

\subsection{CTESias (3)}

\subsubsection{De los tres pasajes, ya hemos adelantado uno al ocuparnos de Heródoto ${ }^{23}$.}

3.2.2-3. Las otras dos apariciones las hallamos en el mismo contexto. El pergameno revisa el texto hipocrático donde se habla de cómo hay que reducir una luxación del muslo ${ }^{24}$ :

Han condenado a Hipócrates por reducir la articulación por la cadera, porque se disloca en seguida; el primero, Ctesias de Cnido, familiar suyo, pues también éste era asclepiada por estirpe, y, después de Ctesias, algunos otros. Pues bien, siendo doble el juicio sobre todos los asuntos tales, uno, cuando alguien es testigo ocular de lo investigado, otro, cuando a partir de su propia naturaleza, sin esperar una larga prueba, muestra algo de modo probativo, también nosotros realizaremos los dos $^{25}$.

${ }^{21}$ El singular no está registrado en el historiador.

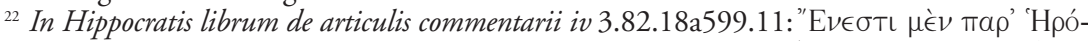

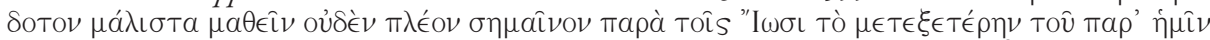



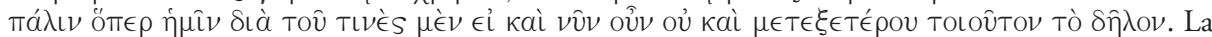
secuencia, si es sana (también tienen esa lectura la Aldina, 1525, 5, p. 190; y la de Basilea, 1538, 5,

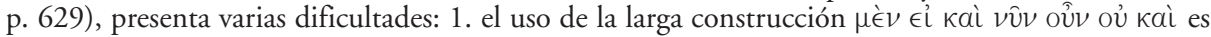
única en la literatura griega; 2. el neutro sustantivado Tò $\delta \hat{\eta} \lambda \circ \nu$ es una rareza en griego, con solo dos precedentes (Arist., Ph. 254b26; Ammon., Diff. 63), y otras dos apariciones en el médico: 17b314.2; 18b848.10. Frente al juicio de nuestro investigador, conviene advertir que Heródoto usa una lengua literaria altamente elaborada, una mezcla de dialectos, que no coincide con la hablada por los jonios en

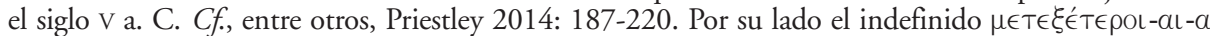
(«algunos entre varios», «determinados») lo leemos a partir de Heródoto (17), Tratados hipocráticos (8 empleos; de ellos siete en plural; el único singular es el ofrecido en Art. 72, ya leído), Nicandro (2), Erotiano (2), Arriano (6), Areteo (60), Galeno (12), etc.

${ }^{23}$ Cf. nota 16.

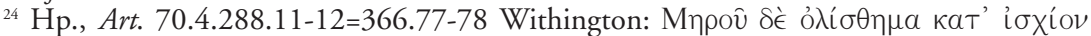

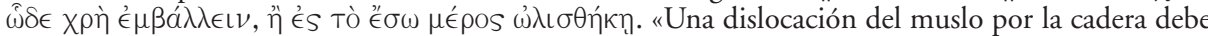
reducirse de la siguiente manera, si se ha dislocado hacia dentro». Entiéndase «muslo» como «hueso del muslo", es decir, el fémur.

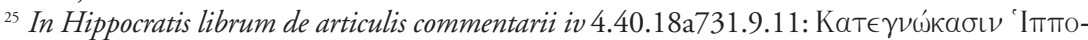

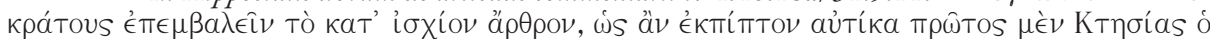

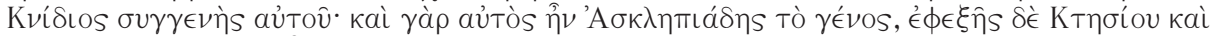

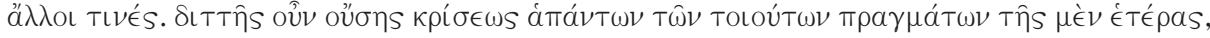




\subsection{JENOFONTE $(7)^{26}$}

\subsubsection{Galeno habla tres veces de este historiador ateniense en su famoso tratado}

De usu partium. Las dos primeras, dentro de su estudio sobre el ojo, donde se detiene en cómo una luz brillante y viva hiere los ojos: «Precisamente, respecto a los soldados de Jenofonte ${ }^{27}$ que caminaron a través de mucha nieve, hasta qué punto sufrieron

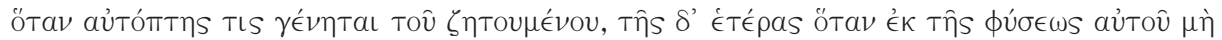

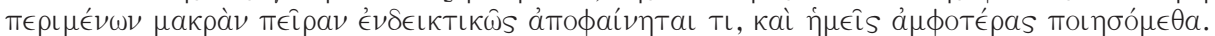
Varios elementos merecen atención: 1. syngenếs indica, por lo común, un cierto grado de parentesco por pertenecer a la misma familia o estirpe; 2. Asklēpiádès, patronímico presente ya en Homero, alude a quien es descendiente o familiar, en algún grado, de Asclepio. Los asclepiadas, diseminados por diversos lugares, tenían en común el conocimiento y la práctica de la medicina, como ilustre legado de su estirpe. El término también designa, por extensión, a los médicos (no debe confundirse con el antropónimo homónimo. Galeno recoge varios personajes de dicho nombre, especialmente Asclepiades de Bitinia). No he hallado ninguna referencia más donde el patronímico «asclepiada» se atribuya al historiador cnidio; 3. autóptès, "testigo ocular», lo leemos desde Heródoto (5); a continuación, entre otros autores, lo registran Arist. (6), Pol. (22), Plut. (6), Gal. (18), etc. 4. endeiktikôs. El adverbio lo leemos una vez en la Carta de Aristeas, y luego en Galeno (19 secuencias, de un total de 34 registradas por el TLG), donde constituye una verdadera aportación: «de modo probativo», «demostrativo». Por lo demás, la secuencia ofrecida es, según el TLG, la única en que hay una relación textual cercana entre Hipócrates-Ctesias.

${ }^{26} \mathrm{La}$ vida del historiador puede encuadrarse entre los años 430-354 a. C. Realmente el antropónimo correspondiente consta en nueve contextos galénicos, pero dos de ellos pertenecen a Jenofonte médico (9.874.16; 18a415.1), el cual floreció hacia el 250 a. C., escribió un libro sobre las partes externas del cuerpo y fue discípulo de Praxágoras. Sobre el citado médico, $c f$. Erotiano, Fr. 32.10.15:

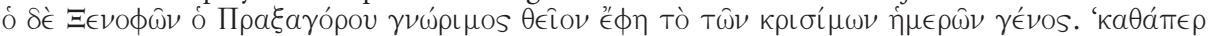

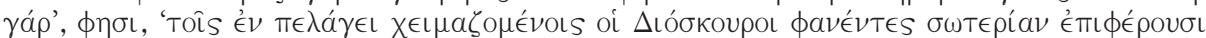

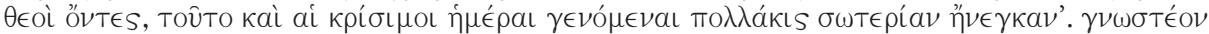


Praxágoras, afirmaba que era divino el género de los días críticos: 'Pues, conforme —afirma - los Dioscuros, siendo dioses, apareciéndose a quienes sufren una tormenta en el mar, les aportan salvación, así los días, cuando son críticos, trajeron muchas veces la salvación'. Ahora bien, se ha de reconocer que Jenofonte se equivoca al afirmar que es sagrado el día crítico». Por su lado, el tratado galénico espurio Introductio seu medicus, 10, 14.700 1-2, lo cita en otra ocasión aludiendo a quienes se habían ocupado de darles nombre a las partes externas del cuerpo. Se dice allí que todo empezó con Aristóteles; luego,

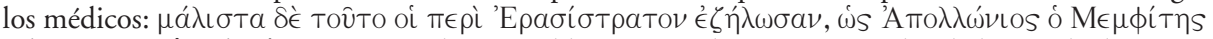

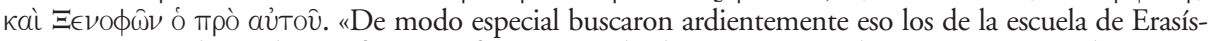
trato, como Apolonio de Menfis, y Jenofonte, antes de él». En este caso el TLG no constata el antropónimo citado, porque el texto de Kühn está borroso y posiblemente no lo registró el aparato reproductor foto-mecánico. En cambio sí consta en la traducción latina correspondiente y, además, en el tomo 20 de Kühn, p. 675, dentro del Index in Galeni libros compuesto por F. W. Assmann. Más noticias sobre el citado médico las ofrece Oribasio en varias ocasiones: 44.15.3, donde lo presenta como discípulo de Praxágoras; 44.15.1, aparece como experto, junto con su maestro, en cierto tipo de úlcera; 45.5.111.5 , se le tiene por especialista en determinada clase de cáncer; etc.

${ }^{27}$ Los hechos principales están recogidos en Anábasis, 4.5.1-15, donde leemos que, soplando un viento del norte que lo helaba todo, el ejército caminaba sobre la nieve, que tenía más de una braza de profundidad; en su larga marcha por una llanura, no lejos del nacimiento del Éufrates, se quedaban atrás, tanto los soldados que tenían dañados los ojos por efecto de la nieve, como aquellos cuyos dedos de los pies padecían gangrena a causa del frío (An. 4.5.12); asimismo leemos una frase de sumo interés médico: «y los ojos tenían una protección de la nieve cuando alguien marchaba teniendo algo 
daños, quizá lo ignoras. Pues no me resulta nada extraño que no te intereses por los escritos de aquél $»^{28}$. Y más adelante, en la misma obra, sigue exponiendo los males que la nieve produce en el citado órgano sensorial: «Pero, el caminar a través de la nieve, hasta qué punto es malo para los ojos, si no crees a Jenofonte, te está permitido aprenderlo mediante una prueba $»^{29}$.

3.3.2. Dentro del libro I de citado escrito el pergameno se extiende sobre la utilidad de la mano y la oportunidad y conveniencia de cada una de sus partes. Sostiene que la mejor belleza es la disposición óptima:

De donde un mercader de esclavos ${ }^{30}$ elogiaría unos cuerpos, pero Hipócrates, otros. $T^{u^{31}}$ piensas quizá que el Sócrates presente en Jenofont ${ }^{32}$ gastaba bromas $^{33}$ al discutir





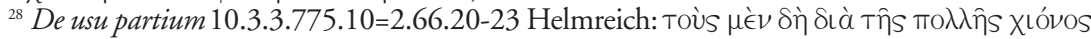

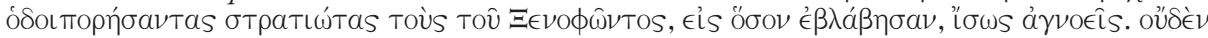


tunas: 1. agnoéo, «desconocer», «ignorar», lo leemos en Hom. (7), los trágicos, Th. (6), Pl. (163), Arist. (136), Gal. (549); 2. La fórmula oudèn thaumastón, «nada extraño», conocida desde Thgn. (1), Th. (1), X. (11), Pl. (22), Isoc. (3), etc., la registra el médico en 243 ocasiones, bien con este orden, bien con el inverso, introduciendo con frecuencia alguna partícula entre ambos términos; 3. la construcción ameleîn grammátōn, en sus distintas posibilidades morfológicas, aparece por primera vez en el prosista. Posteriormente la recogerán unos pocos autores.

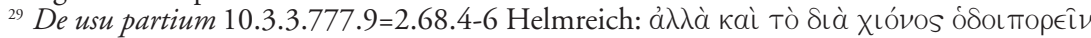

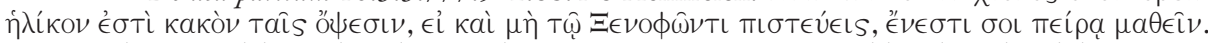
Después de estas palabras, el médico, mediante varios experimentos posibles, dirigidos al destinatario del tratado ( $c f$. nota 31 ), explica cómo una luz más pequeña es vencida por otra más grande y cómo la naturaleza lo previó todo y creó en el ojo la túnica coroides, parcialmente negra, para que la vista cansada pudiera reposar.

${ }^{30} \mathrm{El}$ sustantivo andrapodokápēlos, «mercader de esclavos», lo tenemos, por primera vez, en I. (2) y, luego, en Gal. (7), entre otros. Nuestro médico da bastante información sobre la actividad de tales individuos, especializados en solucionar defectos en personas que los tuvieran: sabían eliminar las manchas de la cara lavándolas con harina de habas (10.998.6), solucionar las partes demasiado delgadas de ciertos niños (10.998.6), incrementarles los glúteos (10.999.3), así como hacerles desaparecer ciertas manchas del rostro (15.459.6).

${ }^{31}$ En ocasiones, nuestro prosista se dirige a un lector anónimo. No en este caso, pues el famoso escrito del que estamos tratando tuvo como destinatario a Boeto. Leemos en De anatomicis administrationibus 1.1.2.217.13 K.=80.11-82.2 Garofalo: «Y, para quien estaba a punto de salir, le escribía yo un tratado extenso Sobre la utilidad de las partes, el cual, habiéndolo terminado en 17 libros, se lo

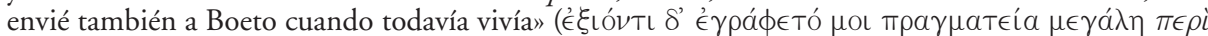

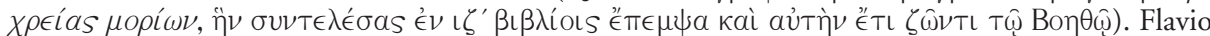
Boeto, que había sido cónsul en los años sesenta, le agradeció siempre al médico haber curado a su mujer y su hijo, y, en prueba de su reconocimiento, lo introdujo en los grupos selectos de la Roma imperial. Nuestro hombre alude a él más de treinta veces: lo presenta como seguidor de la filosofía aristotélica (19.13.6), amante del saber y la belleza, y discípulo del peripatético Alejandro de Damasco (14.627.1). Por otra parte, Galeno manifiesta que había realizado muchas demostraciones anatómicas en casa del mencionado, estando presentes, además, otros ilustres conocidos como el indicado Alejandro y Eudemo el peripatético (2.218.5).

${ }^{32} \mathrm{X}$., Smp. 5.6-7: Sócrates sostiene que tiene ojos, nariz y boca más hermosos que los de Critobulo. Éste era hijo de Critón, personaje central en el homónimo diálogo platónico, y aparece como 
sobre la belleza ${ }^{34}$ respecto a los que parecían ser los más hermosos de su época. Y si él hubiera hablado sencillamente sin referirse a la acción y sin evaluarlo todo mediante ella con respecto a la belleza, quizá solo habría gastado una broma. Pero puesto que en todo el razonamiento atribuye la belleza de la disposición de las partes a la virtud de la acción, no hay que pensar que solo gastaba bromas, sino que también hablaba en serio. Pues esa es la inspiración de Sócrates, mezclar siempre la seriedad con una parte de broma ${ }^{35}$.

3.3.3. El médico, entrando en terreno distinto, insiste en la inutilidad, para la ética y la política, de preguntarse sobre la sustancia de los dioses y si tienen cuerpo o no: «Pues tanto esos asuntos como otros muchos son inútiles para las llamadas virtudes y acciones éticas y políticas, y asimismo para las curaciones de las afecciones propias del alma. Y ha escrito muy bien sobre ellas Jenofonte, no solo condenando su inutilidad, sino afirmando que también Sócrates pensaba así» ${ }^{36}$.

3.3.4. Por último, recojo dos secuencias donde se muestra el interés lingüístico y estilístico de Galeno, así como su refinado gusto literario, pues, al comentar cierto texto hipocrático, recurre a Jenofonte como argumento de autoridad ${ }^{37}$. Por un lado, en

seguidor de Sócrates en varios diálogos de Platón y en obras de Jenofonte (Recuerdos de Sócrates y Banquete); quiso librar a Sócrates de la multa que le impusiera la Heliea (399 a. C.) durante el proceso incoado por impiedad, y, asimismo, estuvo presente en la muerte del maestro. Precisamente en el Banquete jenofonteo se le presenta como amante de Clinias, hijo de Axíoco.

${ }_{33}$ Que Sócrates gustaba de "gastar bromas» (paízō) lo leemos desde X. (Oec. 11.7,17.10, 20.29) y Pl. (Tht.168c; Grg. 481b.bis).

${ }^{34} \mathrm{El}$ sustantivo tò kállos, «la belleza», término homérico, conocido por los trágicos, corriente en el círculo socrático - Pl. (92). X. (29), Isoc.(22)—, bastante utilizado por Arist. (63), se desarrolla mucho en Plut. (141). Gal. (38) lo usa con moderación.

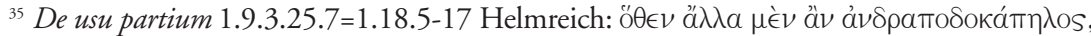

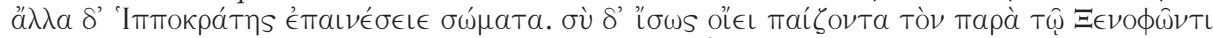

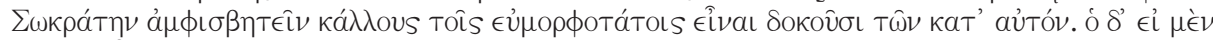

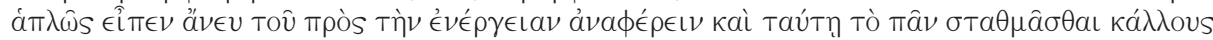

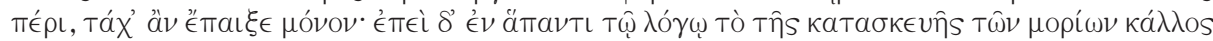

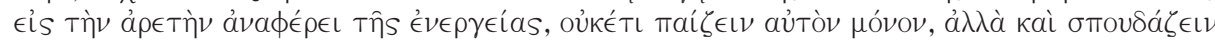

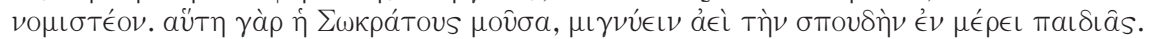

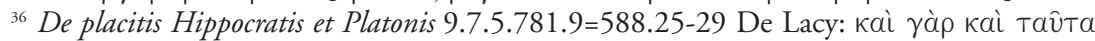

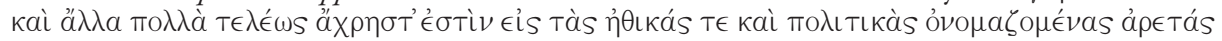

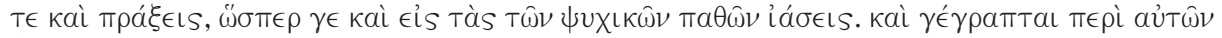

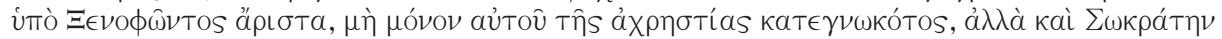

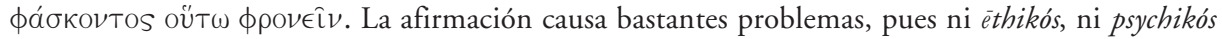
constan en Jenofonte. Un reflejo de la aseveración podría verse en Cyr. 8.6.14, donde se habla de las politikà práxeis, así como en Oec.21.2, a propósito de la politiké, dentro de una enumeración de práxeis, además, en Lac.10.7, donde se alude a la politikè aretế. Por otro lado, el historiador no usa nunca el sustantivo achrèstía, «inutilidad», novedad platónica (3), bien conocida por nuestro médico (10).

${ }^{37}$ Algunos llamaban al historiador «la abeja ática»: Eust., ad Od.1.418.14; Sud., $x$ 47. Gray 2017, 227, resume el juicio sobre lengua y estilo de Jenofonte, casi siempre favorable, emitido por grandes críticos literarios de la posteridad. 
la primera de ellas leemos dos veces el antropónimo. Efectivamente, en el proemio de su Comentario a sobre las articulaciones insiste en que seguirá al Comentario a sobre las fracturas, como había dicho ya en la exegesis dedicada a este tratado. Primero expone cómo comienza el hipocrático Sobre las articulaciones ${ }^{38}$, y, a continuación, afirma:

Y, con respecto a éste, a su vez, justo al comienzo (sc. Hipócrates) escribió la conjunción ${ }^{39}$ dé pues se refiere claramente, con todo, a lo dicho de antemano, pero no comienza jamás una explicación. Ahora bien, algunos han llegado a tal punto de sabiduría que creyendo recordar los Económicos ${ }^{40}$ de Jenofonte para testimoniar que era costumbre para los antiguos usar la conjunción al comienzo de una explicación, afirman por eso que Jenofonte comenzó su obra del siguiente modo: 'Pero lo oí en cierto momento, afirma, dialogando conmigo en tales términos sobre eco-



Por otro, en la Linguarum seu dictionum exoletarum Hippocratis explicatio, como último vocablo de la ómicron, leemos: «otídos ${ }^{44}$ : el ave a la que Aristóteles ${ }^{45}$

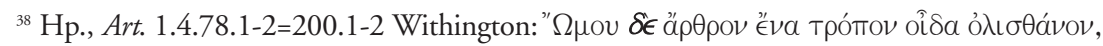
Tò ÉS Tìv $\mu a \sigma \chi \alpha ́ \lambda \eta \nu$ "Pero con respecto a la articulación del hombro conozco solo una manera: la que se produce hacia la axila». Así es el comienzo del tratado hipocrático. Aquí y más abajo, para mayor clari-dad, ofrezco la conjunción en negrita y cursiva.

${ }^{39}$ El sustantivo $\sigma u ́ v \delta \in \sigma \mu O S$, presente en griego desde Tucídides, tiene un amplio espectro semántico: «unión», y de ahí, el valor médico de «ligamento». A partir de Aristóteles cobró un valor nuevo, gramatical: «conjunción», que lo hallamos especialmente en gramáticos posteriores (Dionisio Tracio, Apolonio Díscolo, Hermógenes, etc.). Galeno conoce bien ese sentido. Limitándome a su aparición en relación con gráphō, lo tenemos en: 16.765 .8 (âra; realmente partícula interrogativa); 15.849.11; 16.602.13 (dè); 16.743.1.6.7; 757.8; 17a813.8; 17b167.3; 480.3; 481.5; 18b100.11 (kai); 17a936.5 (mén). Sobre la partícula dé, conectiva-adversativa, $c f$. Denniston, 1970²: 162-189.

${ }^{40}$ Filodemo (Perì oikonomías, col. 6, línea 4; col. 7, lín.28), Plutarco (40c; 515e) y Amonio (Diff. 340) son los únicos que habían mencionado dicha obra de Jenofonte antes que Galeno, donde solo se recoge en esta secuencia.

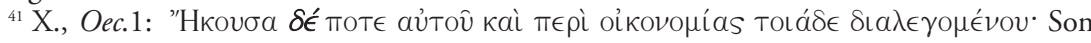
las primeras palabras del escrito jenofonteo.

${ }^{42}$ Galeno es el primero en mencionar los Recuerdos socráticos. El título lo hallamos después en Estobeo, 2.1.30; 31.127; 4.1.37.

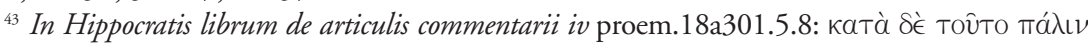

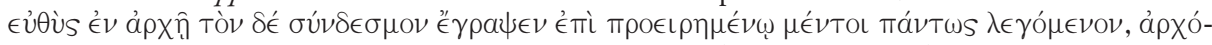

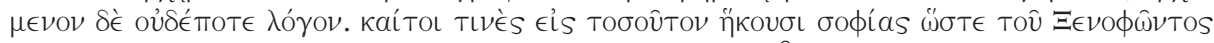

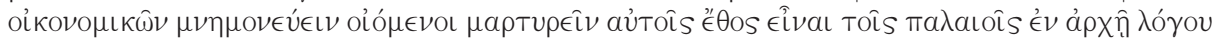

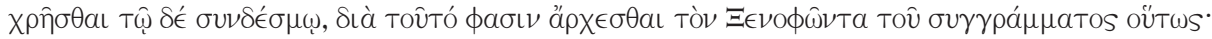

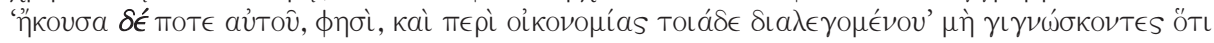



${ }^{44}$ Aparte de este lugar, el médico recoge el vocablo ōtís («avutarda») en tres ocasiones más



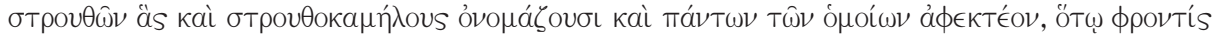

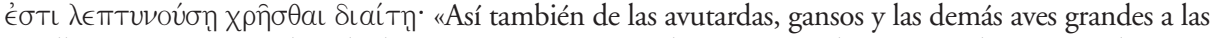
que llaman avestruces y de todas las semejantes tiene que abstenerse aquél que tenga el propósito de seguir 
llama ôtída con la omega, pero Jenofonte, en el primero de la Anábasis ${ }^{46}$ de Ciro, la escribe otída con la ómicron» ${ }^{47}$.

3.4. Con lo expuesto resulta evidente, a mi entender, que, si bien Galeno — con la excepción de Tucídides - no tiene un interés especial por los historiadores (sí lo muestra, en cambio, de modo relevante, por pensadores y filósofos diversos, y, naturalmente, por médicos y comentaristas de los mismos) recurrió a las obras de los más relevantes historiógrafos en busca de apoyo y autoridad tanto en materias médicas como en cuestiones de léxico.

\section{REFERENCIAS BIBLIOGRÁFICAS}

\section{Fuentes ${ }^{48}$}

\subsection{GALENO}

Claudii Galeni opera omnia, vol. 1-20, ed. K. G. KüHN, reimp. Hildesheim, Olms, 1965 (Leipzig, K. Knobloch, 1821-18331) (Con texto griego y traducción latina. Son realmente 22 volúmenes, pues hay $17 \mathrm{~b}$ y $18 \mathrm{~b}$; el 20 no contiene textos, sino un Índice y bibliografía. En las obras de Galeno, para comodidad del lector, utilizo las abreviaturas, o el título completo, tal como aparecen en el Corpus galenicum (CGB) citado más abajo. Tras el libro —en caso de haberloy el capítulo, se señalan el volumen, página y línea de la edición de Kühn. Aunque, según es habitual entre filólogos clásicos, cito por esa publicación, en varias ocasiones me apoyo en editores posteriores, convenientemente indicados. Esta y otras muchas ediciones de autores médicos son ahora de uso público, en línea: http://www.biusante.parisdescartes.fr/histoire/medica/ index.php).

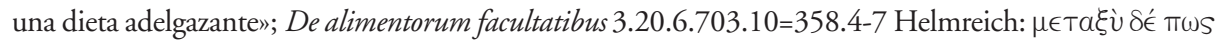

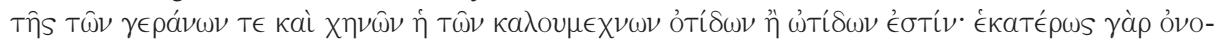

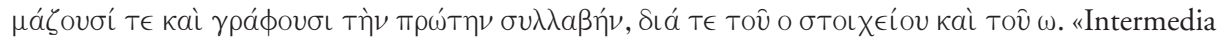
entre la (sc. carne) de cigüeña y de oca, es la de las llamadas otídōn u òtídōn, pues las denominan de las dos formas y escriben la primera sílaba ya con ómicron ya con omega»).

${ }^{45}$ Arist., HA 509a4; 509a22; 539b30; 563a29; 619b13 (las localiza entre los escitas).

${ }^{46} \mathrm{X} .$, An. 1.5.2 y 3 (habla de una región próxima al Éufrates, entre Siria y Arabia). Antes de nuestro prosista hallamos numerosas menciones de la Anábasis (bien así, solo este sustantivo; bien acompañado del genitivo subjetivo, «de Ciro») en: D.H., [Eloc. 3]; Ammon., Diff. 63; Harp. (cuatro citas; en $\zeta 1$ leemos la primera referencia al séptimo (y último) libro de tal obra); Hdn. (seis citas); etc.

${ }^{47}$ Linguarum seu dictionum exoletarum Hippocratis explicatio 19.127.9: como último vocablo

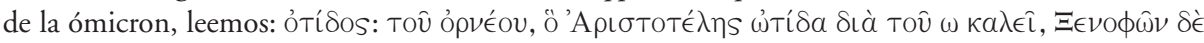

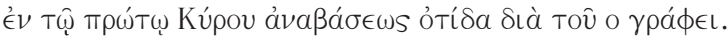

${ }^{48}$ Recojo aquí solamente las ediciones de las que se han tomado los pasajes ofrecidos, o a las que, por cualquier otro motivo, nos hemos referido de modo especial. 
Galeni De placitis Hippocratis et Platonis, ed., trad. ing., com. Ph. DE LACY, vol. I-III. (revisada y aumentada, I3, II-III', Berlín, Aedibus Academiae Scientiarum, 2005). (Berlín, Akademie Verlag, 1978-1984') (CMG v 4.1.2) (Todos los volúmenes del CMG (Corpus Medicorum Graecorum) están disponibles en línea: http://cmg.bbaw.de/epubl/online/editionen.html).

Galeni De usu partium libri XVII, ed. G. HelmreICH, I (Libr. I-VIII), II (Libr. IX-XVII), Leipzig, Teubner, 1907-1909.

Galeni in Hippocratis Epidemiarum librum VI commentaria I-VI, ed. E. WENKEBACH; commentaria VI-VIII, in Germanicam linguam transtulit F. PFAFF, editio altera lucis ope expressa. Berlín, Aedibus Academiae Scientiarum, 1956 (CMG V 10.2.2).

Galeni librorum pars prima [quinta], vol. 1-5, Venecia, Aldo Manucio, 1525 (=Aldina).

Galeni Pergameni summi semper viri quique primus artem medicinae universam... Opera omnia, ad fidem complurium \& perquam vetustorum exemplariorum ita emendata atque restituta, ut nunc primum nata, atque in lucem aedita, uideri possint, vol. 1-5, eds. J. CAMERARIO-L. FuCHS-G. GEMUSEO, Basilea, A. Cratander-J. Bebel, 1538 (=edición de Basilea).

GALENO, Procedimenti anatomici, ed., trad. it., notas I. Garofalo, vol. 1-3, Milán, Rizzoli, 1991.

\subsection{HipóCRATES}

Hippocrate. OEuvres complètes d'Hippocrate, ed. E. LiTTRÉ, vol. 1-10, reimp. Ámsterdam, Hakkert, 1961 (París, J. B. Baillière, 1839-1861) (Contiene texto griego, versión francesa, prólogos ilustradores y abundantes notas. Las citas unificadas de los pasajes hipocráticos remiten al indicado estudioso francés (recojo en cifras arábigas, libro — en caso de haberlo - y capítulo, volumen, página y línea), aunque sigo, en bastantes casos, el texto de editores posteriores, oportunamente indicados).

Hippocrates, ed., trad. ing., E. Th. WithingTON, Londres-Cambridge (Massachusetts), HeinimannHarvard University Press, reimp., 1972 (19281); (Loeb. III) (Contiene, entre otros, Sobre las articulaciones $=$ Art., Sobre el consultorio del médico $=O f f$.)

Hippocrates, ed., trad. ing., W. H. S. JONES, Londres-Cambridge (Massachusetts), Heinimann-Harvard University Press, reimp. 1968 (1931'); (Loeb. IV) (Incluye, entre otros escritos, los Aforismos=Aph.).

\section{Instrumentos léxicos}

Corpus Galenicum. Bibliographie der galenischen und pseudogalenischen Werke, G. FICHTNER et alii, Brandenburgischen Akademie der Wissenschaften, Berlín, mayo 2017 (última revisión; en línea. Abreviado como $C G B$ en este trabajo).

DGE (1980 ss): eds. F. R. Adrados et alii, Diccionario griego-español, Madrid, CSIC.

García Sola, M. C. (1996): «Bibliografía de Galeno», Tempus (Revista de Actualización Científica sobre el Mundo Clásico en España) 14: 5-46.

KollesCh, J.-Nickel, D. (1994): «Bibliographia Galeniana. Die Beiträge des 20. Jahrhundert zur Galenforschung», ANRW 37.2: 1351-1420, 2063-2070.

LSJ (1843'): Greek-English Lexicon, H. G. LIDDELL-R. SCOTT, revis. H. S. JONES et alii, Oxford, Clarendon Press (con muchas reediciones).

LeWIS, Ch. T.-SHORT, Ch. (1879'): A Latin-English Dictionary, Oxford, Clarendon Press (con muchas reediciones). 
Quiroga Puertas, A.-García Sola, M. C. (2013): Galen. Selected Bibliography (1965-2012), Berlín, Logos Verlag.

TLG (2001'): Thesaurus Linguae Graecae, University of California. Irvine (California), en línea.

\section{Estudios}

Boudon-Millot, V. (2012): Galien de Pergame. Un médecin grec à Rome, París, Les Belles Lettres.

DAWSON, W. R.-HARVEY, F. D. (1986): «Herodotus as a medical writer», Bulletin of the Institute of Classical Studies 33: 87-96.

Denniston, J. D. (1970² [1934'1]): The Greek Particles, Oxford, Clarendon Press.

Flower, M. A. (ed.) (2017): The Cambridge Companion to Xenophon, Cambridge, Cambridge University Press.

Gerson, Ll. P. (ed.) (2000): The Cambridge History of Philosophy in Late Antiquity. I, Cambridge, Cambridge University Press.

Gill, C.-Whitmarsh, T.-Wilkins, J. (eds.) (2009): Galen and the World of Knowledge. Greek Culture in the Roman World, Cambridge-Nueva York, Cambridge University Press.

GraY, V. (2017): «Xenophon's Language and Expression», en M. A. Flower (ed), The Cambridge Companion to Xenophon, Cambridge, Cambridge University Press, pp. 222-229.

Hankinson, R. J. (2000): «Galen», en Ll. P. Gerson (ed.), The Cambridge History of Philosophy in Late Antiquity. I, Cambridge, Cambridge University Press, pp. 210-232.

(ed.) (2008): The Cambridge Companion to Galen, Cambridge, Cambridge University Press.

LÓPEZ FÉREZ, J. A. (1992): «Galeno y la literatura griega», en J. ZARAGOZA-A. GONZÁLEZ SENMARTí (eds.), Homenatge a Josep Alsina (Actes X Simposi de la Secció catalana de la SEEC. Universitat de Tarragona. Sociedad Española de Estudios Clásicos. 28-30/11/1990), Tarragona, Diputació de Tarragona, I, pp. 217-224.

(2006): «El Helenismo en Galeno», en V. Boudon-Millot-A. GarzyA-J. JouAnNA-A. Roselli (eds.): Ecdotica e ricezione dei testi medici greci (Atti del v Convegno internazionale sulla Ecdotica dei testi medici greci. Università degli Studi di Napoli Federico II-Istituto Universitario Orientale. 01-02/10/2004), Nápoles, D’Auria, pp. 137-164.

MATTERn, S. P. (2013): The Prince of Medicine: Galen in the Roman Empire, Oxford, Oxford University Press.

Nichols, A. (2008): The complete fragments of Ctesias of Cnidus. Translation and commentary with introduction (Tesis), University of Florida.

(2011): Ctesias. On India and fragments of his minor works. Introduction, translation and commentary, Londres-Nueva Delhi-Nueva York-Sidney, Bloomsbury.

NutTon, V. (2013²; 2004¹): Ancient Medicine, Londres-Nueva York, Routledge.

- (2009): "Galen's Library», en Gill, C.-Whitmarsh, T.-Wilkins, J. (eds), Galen and the World of Knowledge. Greek Culture in the Roman World, Cambridge-Nueva York, Cambridge University Press, pp. 19-34.

Priestley, J. (2014): Herodotus and Hellenistic Culture: Literary Studies in the Reception of the Histories, Oxford-Nueva York, Oxford University Press.

Priestley, J.-Zali, V. (2016): Brill's Companion to the Reception of Herodotus in Antiquity and Beyond, Leiden-Boston, Brill. 
SierRa MARTín, C. (2014): «Heródoto (II. 86-88) y el conocimiento anatómico griego», Ágora: estudos clássicos em debate 16: 29-40.

SCHLANGE-SCHÖNInGEN, H. (2003): Die römische Gesellschaft bei Galen: Biographie und Sozialgeschichte, Berlín-Nueva York, Walter de Gruyter.

STRONK, J. P. (2010): Ctesias' Persian History: Introduction, text, and translation, Wellen Verlag, Düsseldorf.

Thomas, R. (2002): Herodotus in Context: Ethnography, Science and the Art of Persuasion, Cambridge University Press. 
